\title{
Hypertensive Emergency and Type 2 Myocardial Infarction Resulting From Pheochromocytoma and Concurrent Capnocytophaga Canimorsus Infection
}

\author{
Graham J. Fent*, Hazlyna Kamaruddin, Pankaj Garg, Ahmed Iqbal, Nicholas F. Kelland and Ian R. Hall
}

Northern General Hospital, Herries Road, Sheffield, South Yorkshire, UK S5 7AU

\begin{abstract}
A diagnosis of myocardial infarction is made using a combination of clinical presentation, electrocardiogram and cardiac biomarkers. However, myocardial infarction can be caused by factors other than coronary artery plaque rupture and thrombosis. We describe an interesting case presenting with hypertensive emergency and type 2 myocardial infarction resulting from Pheochromocytoma associated with Capnocytophaga canimorsus infection from a dog bite. We also review current literature on the management of hypertensive emergency and Pheochromocytoma.
\end{abstract}

Keywords: Capnocytophaga Canimorsus, Myocardial Infarction, Pheochromocytoma, Systemic Hypertension, Sepsis,.

\section{INTRODUCTION}

Myocardial infarction is frequently due to coronary artery thrombosis from a ruptured atherosclerotic plaque, necessitating early thrombolytic therapy or primary percutaneous coronary intervention (PPCI) to minimise myocardial damage. Myocardial injury, symptoms and ECG changes consistent with MI can also result from an imbalance between myocardial oxygen delivery and/ or demand which is categorized as type 2 MI [1]. Although the decision to proceed to urgent PPCI needs to be made without delay, cases with a more unusual presentation require careful assessment to avoid unnecessary complications and overlooking important differential diagnoses. We present an unusual case of a patient presenting with hypertensive emergency and type 2 MI, precipitated by a previously undiagnosed pheochromocytoma, associated with infection from a dog bite.

\section{CASE REPORT}

A 58-year caucasian male with a past medical history of hypertension and medically treated MI 20 years previously, presented to the emergency department with marked diaphoresis, shivering, mild headache, neck pain and vomiting. Vital signs on presentation included blood pressure of 205/107 $\mathrm{mmHg}$, heart rate of 68 beats per minute and temperature of $36.6^{\circ} \mathrm{C}$. Clinical examination revealed normal heart sounds and mild crepitations at both lung bases. Initial ECG showed sinus rhythm with ST elevation and peaked $\mathrm{T}$ wave in leads $\mathrm{V} 1-\mathrm{V} 3$ and ST-depression in the lateral leads (Fig. 1).

\footnotetext{
*Address correspondence to this author at the Department of Cardiology, Chesterman Wing, Northern General Hospital, Herries Road, Sheffield, S5 7AU; Tel: 01142714950; Fax: 01142610350 ;

E-mail: graham.fent@sth.nhs.uk
}

Blood pressure was controlled with intravenous glyceryltrinitrate and an immediate cardiology consult was made for consideration of PPCI. Transthoracic echocardiography (TTE) showed severe anterior and anteroseptal hypokinesia and overall moderate to severe LV systolic function. Urgent CT aortogram was organised to rule out acute aortic syndrome. This showed no evidence of aortic dissection, but demonstrated a $6 \mathrm{~cm}$ right adrenal mass (Fig. 2). PPCI was deferred due to his lack of chest pain, and the likelihood of his presentation being due to hypertensive emergency.

Laboratory data was significant in showing neutrophils $25.8 \times 10^{9} / 1,12$-hour high sensitivity troponin T $2002 \mathrm{ng} / \mathrm{L}$, C-reactive protein $477 \mathrm{umol} / \mathrm{L}$, creatinine $205 \mathrm{umol} / \mathrm{L}$ and Gram negative rods on blood culture (later confirmed as Capnocytophaga canimorsus). A provisional diagnosis of pheochromocytoma was suggested because of the clinical presentation with hypertensive crisis and adrenal mass on CT. The endocrine team were consulted at this stage. They reviewed the patient and agreed that the most likely diagnosis was pheochromocytoma and commenced the patient on a non-selective, irreversible oral alphaadrenoceptor blocker - phenoxybenzamine. Once postural drop in blood pressure was noted, the patient was cautiously commenced on propranolol. On the advice of microbiology and infectious diseases team he was also commenced on the intravenous antibiotic; piperacillin/tazobactam as per the sensitivities on blood culture.

He began to improve over the next 5 days and on further questioning recalled having been bitten on the hand by a dog prior to his symptom onset. Subsequent diagnostic coronary angiography showed a moderate mid LAD stenosis with no significant reversal on myocardial perfusion imaging and repeat TTE showing mild LV systolic impairment Fig. $(\mathbf{3}, \mathbf{4})$. Urinary metanephrines confirmed Pheochromocytoma and he underwent successful laparoscopic adrenalectomy two months later (Table 1). 


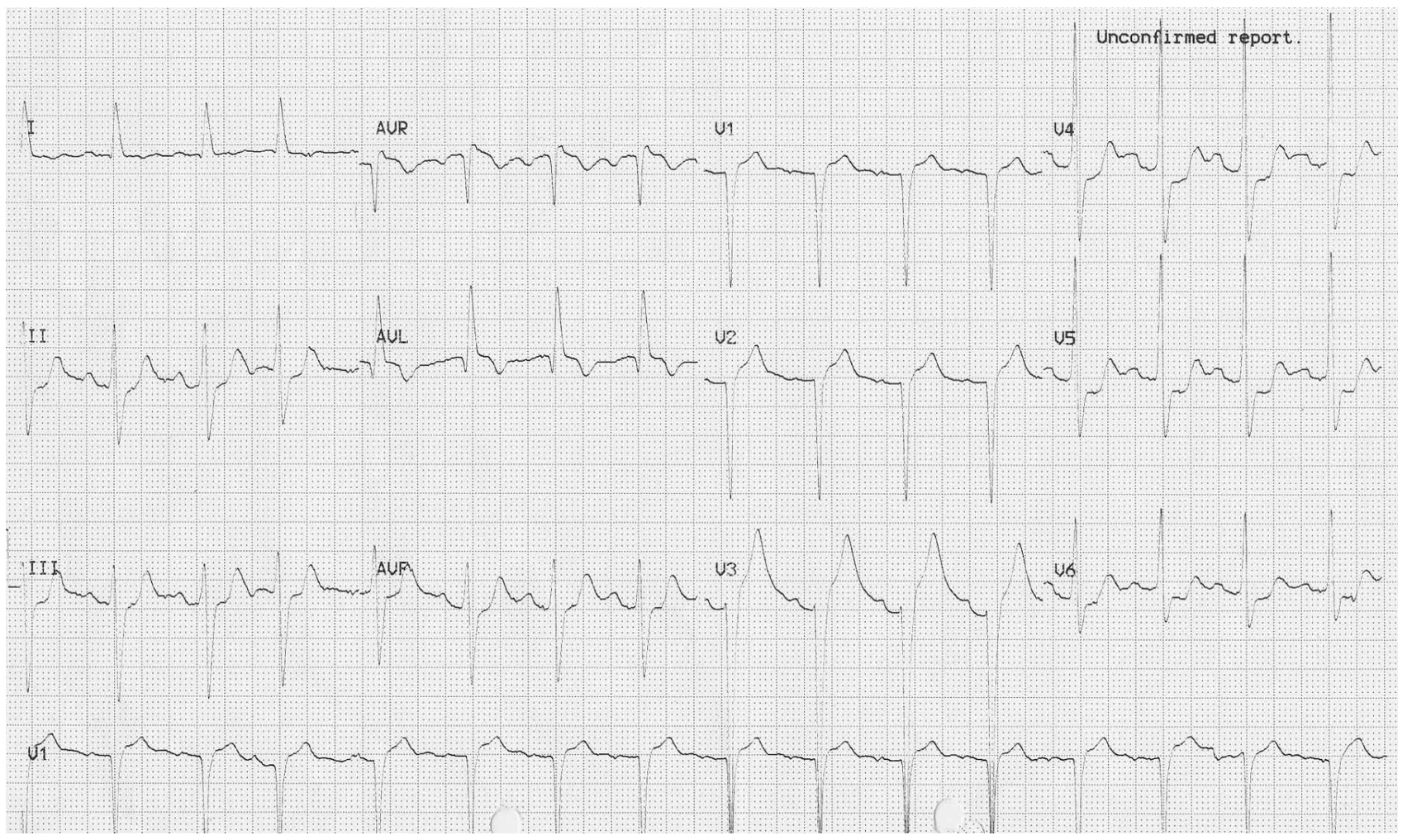

Fig. (1). 12 lead electrocardiogram on initial presentation.

Table 1. Biochemistry results of urine samples.

\begin{tabular}{|c|c|c|}
\hline Investigations & Result & Normal Range \\
\hline \hline $24 \mathrm{hr}$ Urine Metanephrines & 108.7 & $1.7-2.0$ \\
\hline $24 \mathrm{hr}$ Urine Normetanephrines & 104.7 & $4.0-4.8$ \\
\hline $24 \mathrm{hr}$ Urine Noradrenalin & $49763 \mathrm{nmol} / 24 \mathrm{~h}$ & $93-112 \mathrm{nmol} / 24 \mathrm{~h}$ \\
\hline $24 \mathrm{hr}$ Urine Adrenalin & $30378 \mathrm{nmol} / 24 \mathrm{~h}$ & $3400-3850 \mathrm{nmol} / 24 \mathrm{~h}$ \\
\hline $24 \mathrm{hr}$ Urine Dopamine & $4402 \mathrm{nmol} / 24 \mathrm{~h}$ & \\
\hline
\end{tabular}

\section{DISCUSSION}

Hypertensive emergency is defined as elevated systolic or diastolic BP (>180 or $120 \mathrm{mmHg}$ respectively) associated

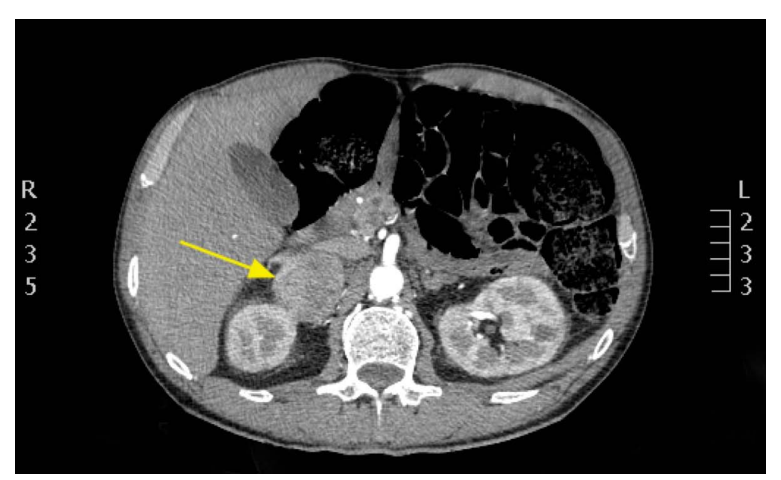

Fig. (2). Contrast Computerised Tomography of abdomen showing adrenal mass (Yellow Arrow). with impending or resultant end organ damage including encephalopathy, acute kidney injury, pulmonary oedema and acute LV impairment [2].

Treatment of hypertensive emergency should be undertaken in a closely observed environment with appropriate arterial BP monitoring and tailored according to its aetiology and the associated end organ damage [3]. With the exception of aortic dissection where BP should be rapidly reduced, BP in patients with hypertensive emergency should be lowered gradually over the first hour with intravenous medications before instituting oral therapy [4].

In this case, where there was evidence of early pulmonary oedema and LV impairment with suspected Pheochromocytoma; the patient was treated with intravenous glyceryltrinitrate followed by oral phenoxybenzamine. It should be emphasised that administration of beta-blocker medication in the setting of sympathetic crisis such as that caused by Pheochromocytoma, could lead to unopposed alpha-adrenergic activity and resulting in a paradoxical rise 


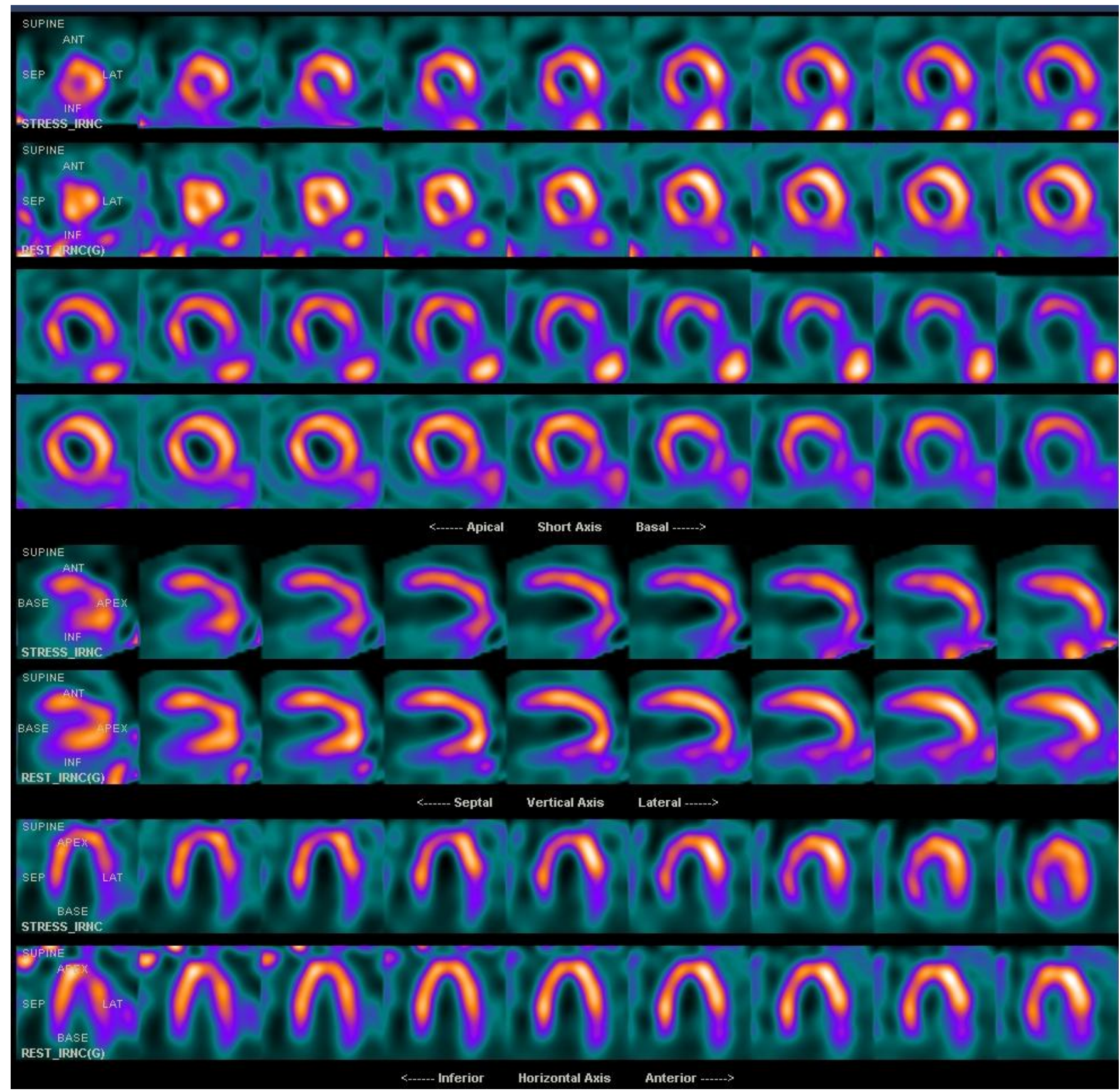

Fig. (3). Myocardial perfusion scintigraphy showing basal inferior scaring and mid/apical inferior wall ischaemia.

in blood pressure [4]. For this reason, alpha-blockers should be introduced initially followed by cautious introduction of beta-blockade therapy later [5]. Following medical stabilisation, laparoscopic surgery is the treatment of choice for Pheochromocytoma [6].

Catecholamine-secreting tumours that arise from the chromaffin cells of the adrenal medulla are called Pheochromocytomas [7]. The latter are rare tumours with an annual incidence of 2 to 8 cases per 1 million people [8]. The clinical presentation with symptoms attributable to sustained hypertension as demonstrated in our case resulted as a consequence of the pharmacological action of excess circulating catecholamines. The clinical context and the imaging phenotype of a large $(>3 \mathrm{~cm})$, albeit unilateral adrenal lesion on contrast CT was highly suggestive of a de novo diagnosis of a Pheochromocytoma. In our patient, the dog bite resulted in overwhelming sepsis, which precipitated the Pheochromocytoma crisis with release of catecholamines. We confirmed our diagnosis biochemically by measuring fractionated catecholamines and metanephrines in urine.

Our patient had ECG evidence of myocardial ischaemia, LV regional wall motion abnormalities on TTE and raised high sensitivity troponin $\mathrm{T}$ assay demonstrating myocardial injury (Fig. 1). We felt this was most likely due type $2 \mathrm{MI}$, in this case resulting from increased myocardial oxygen demand on a background of fixed pre-existing athero- 

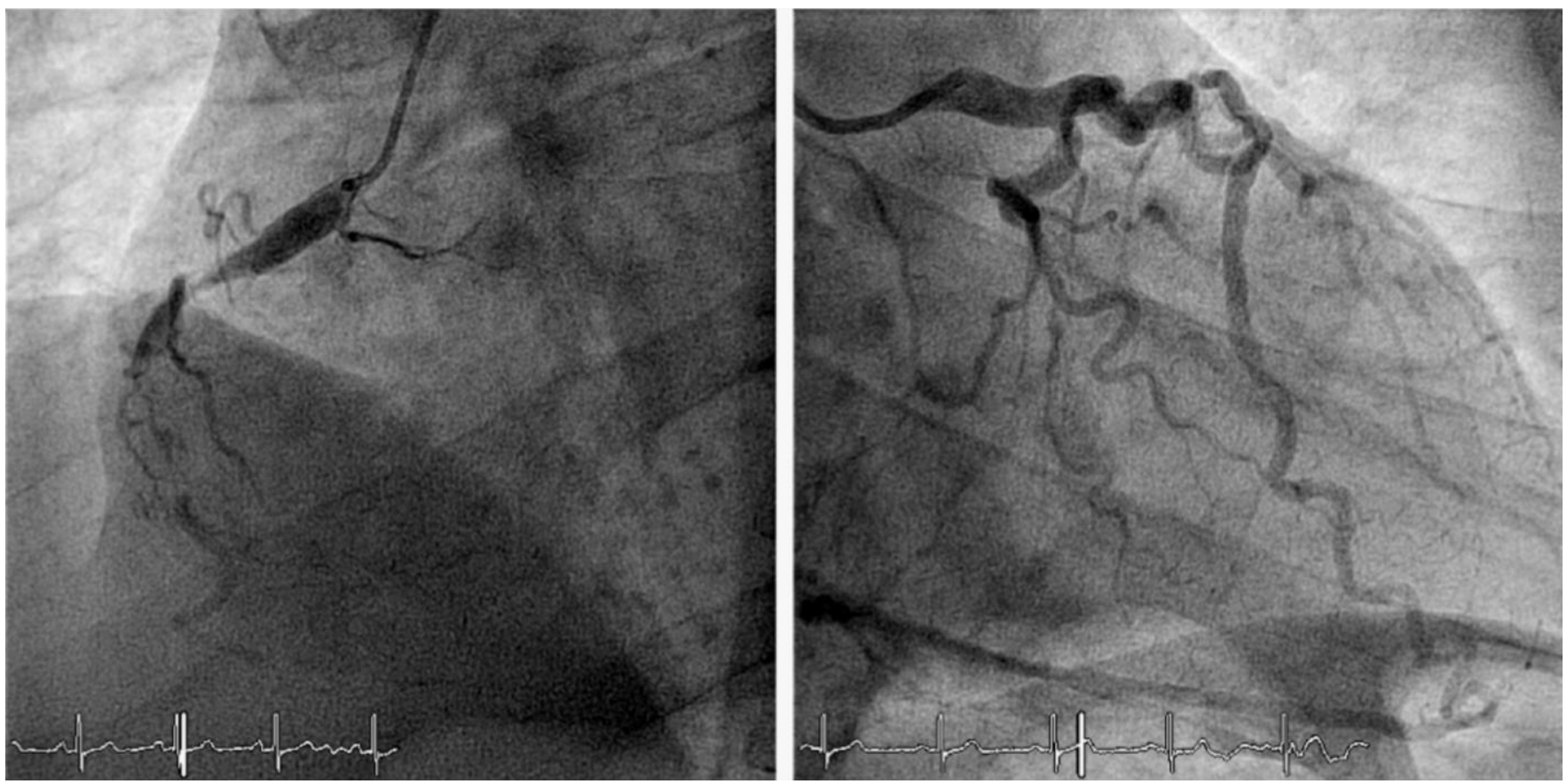

Fig. (4). Invasive coronary angiography showing moderate disease in left anterior descending artery and chronic total occlusion of RCA with retrograde filling from left system.

sclerotic coronary artery disease. Elevated values of cardiac biomarkers can also occur due to direct toxic effects of high levels of endogenous or exogenous catecholamines [1].

\section{CONCLUSION}

Hypertensive emergency can cause a variety of end organ damage including type 2 MI. Pheochromocytoma is a cause of hypertensive emergency and is treated with prompt antihypertensive therapy, alpha-blockade followed by betablockade and eventual surgery. As far we are aware, a case of a dog bite resulting in sepsis by Capnocytopha gacanimorsus provoking a Pheochromocytoma hypertensive crisis and type 2 MI has not been reported previously (literature searched in pubmed.gov using the following words 'Pheochromocytoma capnocyto phagacanimorsus myocardial infarction' on the $3^{\text {rd }}$ of February 2014). A multidisciplinary approach involving cardiology, microbiology, endocrinology, endocrinesurgery and radiology was essentialin making an early diagnosis and implementing appropriate management of his condition.

\section{ABBREVIATIONS}

$\begin{array}{llll}\mathrm{BP} & = & \text { Blood Pressure } & \\ \mathrm{CT} & = & \text { Computerised Tomography } & \\ \mathrm{ECG} & = & \text { Electrocardiogram } & \\ \mathrm{LAD} & = & \text { Left Anterior Descending artery } & \\ \mathrm{LV} & = & \text { Left Ventricle } & \\ \mathrm{MI} & = & \text { Myocardial Infarction } & \\ \mathrm{PPCI} & = & \text { Primary Percutaneous } & \text { Coronary } \\ & & \text { Intervention } & \\ \mathrm{TTE} & = & \text { Transthoracic Echocardiography } & \end{array}$

\section{CONFLICT OF INTEREST}

All authors declare that they have no competing interests.

\section{ACKNOWLEDGEMENTS}

We acknowledge the following individuals for their contribution to the case management and details: Mr Barney Harrison (Consultant Endocrine Surgeon), Royal Hallamshire Hospital; Dr Jonathan Webster (Consultant Endocrinologist), Northern General Hospital; Dr William Bennet (Consultant Endocrinologist), Northern General Hospital; Dr AmitAllahabadia (Consultant Endocrinologist), Northern General Hospital.

\section{REFERENCES}

[1] Thygesen K, Alpert JS, Jaffe AS et al. Third universal definition of myocardial Infarction. Eur Heart J 2012; 33: 2551-67.

[2] The fifth report of the Joint National Committee on detection, evaluation, and treatment of high blood pressure. Arch Intern Med $1993 ; 153: 154-83$.

[3] Manica G, Fagard R, Narkicwicz K et al. 2013 ESH/ESC guidelines for the management of arterial hypertension: the task force the management of artriel hypertension of the European Society of hypertension (ESH) and of the European Society of Cardiology (ESC). 2013.

[4] Marik PE, Varon J. Hypertensive crises challenges and management. Chest 2007; 131: 1949-62.

[5] Pacak K, Eisenhofer G, Ahlman H et al. Pheochromocytoma: recommendations for clinical practice from the $1^{\text {st }}$ International Symposium. Nature 2007; 3 (2): 92-102.

[6] Janetschek G, Finkenstedt G, Gasser R, et al. Laparoscopic surgery for Pheochromocytoma: adrenalectomy, partial resection, excision of paraganglionomas. J Urol 1998; 160: 330-4.

[7] Lloyd RV, Tischer AS, Kimura N, et al: Adrenal tumors: introduction. In: DeLellis RA, Lloyd RV, Heitz PU, et al Eds. 
World Health Organization classification of tumours: pathology and genetics of tumours of endocrine organs, Lyon, France: IARC Press; 2004:136-8.
[8] Stenstrom G, Svardsudd K. Pheochromocytoma in Sweden, 19581981: an analysis of the national cancer registry data. Acta Med Scand 1986; 220: 225-32.

Received: March 14, 2014

Revised: May 06, 2014

Accepted: May 07, 2014

(C) Fent et al.; Licensee Bentham Open.

This is an open access article licensed under the terms of the Creative Commons Attribution Non-Commercial License (http://creativecommons.org/licenses/ by-nc/3.0/) which permits unrestricted, non-commercial use, distribution and reproduction in any medium, provided the work is properly cited. 